\title{
Response of Four Ornamental Shrubs to Container Substrate Amended with Two Sources of Raw Paper Mill Sludge
}

\author{
Calvin Chong' and R.A. Cline ${ }^{1}$ \\ Ontario Ministry of Agriculture and Food, Horticultural Research Institute of \\ Ontario, Vineland Station, Ont. LOR 2EO, Canada
}

Additional index words. nursery production, woody plants, foliar nutrients, waste recycling, organic matter

\begin{abstract}
Four deciduous ornamental shrubs \{'Coral Beauty' cotoneaster (Cotoneaster dammeri C.K. Schneid.), 'Flaviramea' dogwood (Cornus sericea L.), 'Lynwood' forsythia (Forsythia xintermedia Zab.), and 'Variegata' weigela [Weigela florida (Bunge) A. DC.]\} were grown in trickle-irrigated containers with $100 \%$ pine bark (control) or with 10 other pine-bark-amended media, including two sources [Noranda Forest (NF) and Quebec and Ontario (QO)] of raw paper mill sludge mixed at $15 \%$ or $30 \%$ (by volume). All species grew equally well or better in the sludge-amended media than in the control or other nonsludge media. Cotoneaster and forsythia grew more in NF sludge media than in corresponding QO media due primarily to the greater quantities of $\mathrm{N}$ and other nutrients released from the NF sludge.
\end{abstract}

The paper manufacturing process produces large quantities of organic waste products, often referred to as sludge. The high fibrous content makes this material ideally suited to improving the physical properties of soil (Cline and Chong, 1991; Logan and Esmaeilzadeh, 1985; Zibilske, 1987). In addition, nutrients in certain sludges may be beneficial for plant growth (Henry, 199 1; Pridham and Cline, 1988).

Previous research has demonstrated that paper mill sludge can be used as a soil amendment for field-grown agricultural (Cline and Chong, 1991; Logan and Esmaeilzadeh, 1985) and forest (Bockheim et al., 1988; Henry, 1991 ) crops. Paper mill sludge mixed with soi also was effective for growing a variety of greenhouse crops (Cline and Chong, 1991). Similar results were obtained in container nursery culture, but media with more than one-third, by volume, of raw paper mill sludge depressed growth of 'Coral Beauty' cotoneaster, 'Flaviramea' dogwood, 'Lynwood' forsythia, 'Bristol Ruby' weigela (Weigela Thunb.), and 'Anthony Waterer' spiraea(Spiraea $\times$ bumalda Burv.) (Chong et al., 19914 Cline and Chong, 1991). These container studies were limited to paper mill sludge and bark mixtures. In this

\footnotetext{
Received for publication 21 Oct. 1992. Accepted for publication 12 Apr. 1993. This project was supported in part by the Landscape Ontario Horticultural Trades Foundation, Mississauga, Ont. Plant material was donated by Willowbrook Nurseries, Fenwick, Ont. Paper mill sludges were supplied by the Quebec and Ontario Paper Co., Thorold, Ont., and the Noranda Forest Recycled Papers, Thorold. Technical assistance was provided by Bob Hamersma and Debbie Norton. The cost of publishing this paper was defrayed in part by the payment of page charges. Under postal regulations, this paper therefore must be hereby marked advertisement solely to indicate this fact.

'Research Scientist.
}

study, we investigated a wider assortment of medium components, with a maximum raw paper mill sludge content of $30 \%$ from two paper manufacturers.

On 15 May 1991, plug-rooted liners of 'Coral Beauty' cotoneaster, 'Flaviramea' dogwood, 'Lynwood' forsythia, and 'Variegata' weigela were transplanted to 6 -liter $(21 \mathrm{~cm}$ in diameter $\times 21 \mathrm{~cm}$ deep) nursery containers. Liners of forsythia were 5 to $8 \mathrm{~cm}$ tall; all others were 12 to $15 \mathrm{~cm}$. We tested 11 media (Table 1), including a control of $100 \%$ composted pine bark (2-cm mesh size), and eight others containing one of two sources [Quebec and Ontario (QO) Paper Co. and Noranda Forest (NF) Recycled Papers] of raw paper mill sludge mixed at $15 \%$ or $30 \%$ (by volume).

Three types of sludge are produced: primary, which is derived directly from the paper-making process and contains wood fibers; secondary, which has been subjected to microbial breakdown and contains supplementary $\mathrm{N}$ and $\mathrm{P}$, and tertiary, from de-inked recycled paper (Cline and Chong, 1991). The QO sludge is a mixture of $70 \%$ primary and $30 \%$ secondary sludge that contains $=1.2 \% \mathrm{~N}$ (dry-weight basis). The NF sludge is a mixture of $90 \%$ primary and $10 \%$ secondary sludge and initially contains less $\mathrm{N}(0.35 \%)$ than the QO sludge. Thus, NF Papers routinely adds ammonium nitrate to increase the total $\mathrm{N}$ content of the sludge to $\approx 1.2 \%$ before disposal on agricultural land to aid subsequent microbial breakdown (Bellamy et al., 1990). Both sources have low levels of heavy metals (Bellamy, 1989; Pridham and Cline, 1988) and various organo-chloride compounds that are within guidelines in the United States (U.S. Environmental Protection Agency, 199 1) and Ontario. Secondary sludge is high in $\mathrm{N}$ and $\mathrm{P}$, while primary sludge is low in these nutrients. Since secondary sludge may induce excessive growth, a combination of primary and secondary sludges maybe more appropriate as amendments (Pridham and Cline, 1988). The sludges were coarsely ground (1.0 to $1.5 \mathrm{~cm}$ in diameter) before mixing.

This research was conducted outdoors in the experimental container nursery at the Horticultural Research Institute of Ontario, Vineland Station. Cotoneaster and weigela were spaced $45 \times 45 \mathrm{~cm}$, and the other two species $60 \times 45 \mathrm{~cm}$, each arranged in a separate randomized complete block design with five replications and four plants per plot. Plants were trickle-irrigated with 2 liters water/container daily and fertilized through the irrigation system three times weekly with $200 \mathrm{mg} \mathrm{N} /$ liter applied as a $20 \mathrm{~N}-8.7 \mathrm{P}-16.6 \mathrm{~K}$ watersoluble fertilizer that also contained the following micronutrients (in $\mathrm{mg} \cdot \mathrm{liter}^{-1}$ ): $\mathrm{Fe}, 1.0$; Mn, 0.5; Zn, 0.5; Cu, 0.5; and Mo, 0.005 (Plant Products, Brampton, Ont.). In previous experiments, this management system has been successful in producing marketable plants in one growing season. Also, treatment differences occured the first year. For these reasons, the experiment was conducted in one growing season. Preplant amendments such as limestone and micronutrients were not required.

At planting, duplicate samples of all experimental media were analyzed for $\mathrm{pH}$, electrical conductivity (EC) [1 medium :2 water extracts $(\mathrm{v} / \mathrm{v})]$, and mineral nutrients (Table 1), and triplicate samples for selected physical properties (Chong et al., 1991 b). EC and $\mathrm{pH}$ were also measured on 22 Aug. from medium samples collected (7- to $12-\mathrm{cm}$ depth) from each treatment.

Recently matured leaves were sampled in mid-August and analyzed for total N, P, K, Ca, $\mathrm{Mg}, \mathrm{Fe}, \mathrm{Mn}$, and Zn (Chong et al., 1991 b). In early October, the width (cotoneaster) or height (all other cultivars) of each plant and the shrinkage of the medium in each pot, expressed as depth from the container rim, were recorded. Tops (stem with leaves) were dried at 50C for 4 weeks in a forced-air dryer and weighed.

Although cultivars responded differently to the various media, plants of all cultivars and treatments were of marketable size when harvested in early October, except those of forsythia, which were started from smaller liners. Unlike the other species, weigela growth was unaffected by media (Table 2).

Contrast analysis indicated greater top dry weight of dogwood and cotoneaster in the sludge-amended media than in the control (100\% bark) medium (Table 2; Fig. 1). Forsythia growth in the sludge-amended media was similar to that in the control. Only cotoneaster growth in the nonsludge media $(75 \% \mathrm{~B}$ :15\% P: $10 \%$ S and $60 \%$ B: $30 \%$ P: $10 \%$ S) was significantly greater than in the control (also a nonsludge medium).

Among the sludge-amended media, top dry weight of cotoneaster and forsythia was greater in all four NF media than in corresponding QO media (Table 2; Fig. 1). Dogwood growth was similar with NF or QO sludge. Although contrast analysis indicated 
Table 1. Chemical analysis of the experimental media at planting.

\begin{tabular}{|c|c|c|c|c|c|c|c|c|c|c|c|c|c|c|}
\hline \multicolumn{4}{|c|}{$\begin{array}{c}\text { Media } \\
(\% \text { by vol }) \\
\end{array}$} & \multirow[b]{2}{*}{$\mathrm{pH}$} & \multirow{2}{*}{$\begin{array}{c}\mathrm{EC}^{\mathrm{y}} \\
\left(\mathrm{dS} \cdot \mathrm{m}^{-1}\right)\end{array}$} & \multirow[t]{2}{*}{$\mathrm{NO}_{3}$} & \multirow[t]{2}{*}{$\mathrm{P}$} & \multirow[t]{2}{*}{$\mathrm{K}$} & \multirow[t]{2}{*}{$\mathrm{Ca}$} & \multirow{2}{*}{$\begin{array}{c}\mathrm{Mg} \\
\left(\mathrm{mg} \cdot \text { liter }^{-1}\right)\end{array}$} & \multirow[t]{2}{*}{$\mathrm{Cl}$} & \multirow[t]{2}{*}{$\mathrm{Fe}$} & \multirow[t]{2}{*}{$\mathrm{Mn}$} & \multirow[t]{2}{*}{$\mathrm{Zn}$} \\
\hline B & $\mathrm{P}$ & QO & $\mathrm{NF}$ & & & & & & & & & & & \\
\hline$\overline{100}$ & $\begin{array}{ll}x & ---\end{array}$ & --- & --- & $7.0^{w}$ & 0.3 & 1 & 2 & 62 & 47 & 4 & 8 & 0.2 & 0 & 0 \\
\hline 75 & 15 & --- & --- & 7.4 & 0.5 & 12 & 1 & 37 & 42 & 6 & 14 & 0.3 & $<0.1$ & $<0.1$ \\
\hline 75 & --- & 15 & --- & 7.4 & 0.4 & 6 & 2 & 34 & 33 & 8 & 13. & 0.6 & $<0.1$ & 0.2 \\
\hline 75 & --- & --- & 15 & 7.1 & 5.2 & 456 & 0 & 84 & 450 & 35 & 42 & 0.3 & $<0.1$ & $<0.1$ \\
\hline 60 & 30 & --- & --- & 6.7 & 0.3 & 2 & 2 & 26 & 30 & 6 & 18 & 0.3 & $<0.1$ & $<0.1$ \\
\hline 60 & --- & 30 & --- & 7.7 & 0.4 & 1 & 1 & 24 & 26 & 5 & 20 & 0.3 & $<0.1$ & 0.4 \\
\hline 60 & --- & --- & 30 & 6.8 & 7.6 & 1063 & 0 & 84 & 525 & 42 & 68 & 0.2 & 0.2 & $<0.1$ \\
\hline 60 & 15 & 15 & --- & 7.3 & 0.6 & 45 & 2 & 30 & 40 & 7 & 30 & 0.5 & $<0.1$ & 0.2 \\
\hline 60 & 15 & --- & 15 & 7.0 & 4.1 & 625 & 0 & 80 & 375 & 32 & 42 & 0.3 & $<0.1$ & $<0.1$ \\
\hline 30 & 30 & 30 & --- & 6.9 & 0.8 & 54 & 0 & 18 & 46 & 8 & 22 & 0.6 & $<0.1$ & 0.2 \\
\hline 30 & 30 & --- & 30 & 6.9 & 6.2 & 900 & 0 & 40 & 435 & 35 & 61 & 0.2 & 0.1 & $<0.1$ \\
\hline
\end{tabular}

${ }^{2} \mathrm{~B}=$ pine bark $\mathrm{P}=$ peat; $\mathrm{QO}=$ Quebec and Ontario paper mill sludge; NF = Noranda Forest paper mill sludge. All, except the control, contained 10\% sand.

${ }^{y} \mathrm{EC}=$ electrical conductivity.

'Control.

'Each datum is an average of two samples.

Table 2. Analysis of variance of top dry weight of nursery crop cultivars grown in 11 experimented media.

\begin{tabular}{lccccc}
\hline & & \multicolumn{4}{c}{ Mean squares } \\
\cline { 3 - 6 } Source & df & Dogwood & Cotoneaster & Forsythia & Weigela \\
\hline Media & 10 & $9247^{* *}$ & $2807^{* *}$ & $1000^{* *}$ & $118^{\mathrm{NS}}$ \\
Replication & 4 & $5683^{*}$ & 652 & $1524^{* *}$ & $323^{*}$ \\
Error & 40 & 1780 & 505 & 162 & 92 \\
Contrasts & & $* *$ & NS & NS \\
Sludge-amended vs. control & $*$ & $*$ & $* *$ \\
Nonsludge vs. control & NS & $* *$ & $* *$ \\
NF sludge vs. QO sludge & NS & $* *$ & \\
30\% Sludge vs. 15\% sludge $* *$ & & &
\end{tabular}

\section{${ }^{2}$ Defined in Table 1}

${ }_{\mathrm{Ns}, *, *}^{*, *}$ Nonsignificant or significant at $P \leq 0.05$ or 0.01 , respectively.
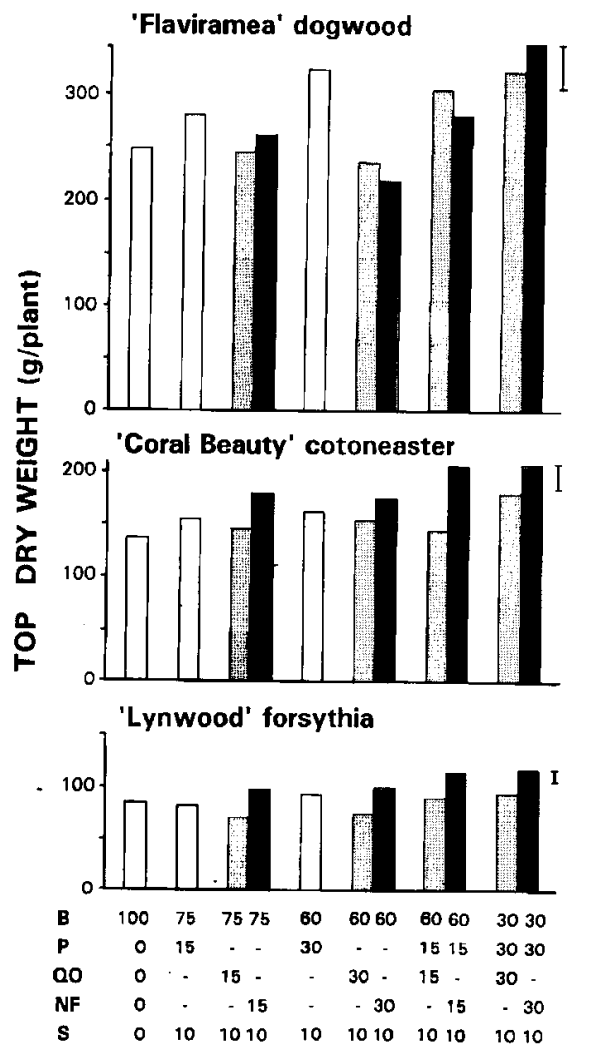

Fig. 1. Top dry weight of three nursery crop cultivars grown in 11 experimental media. $\mathrm{B}=$ pine bark; $\mathrm{P}=$ peat; $\mathrm{QO}=\mathrm{Quebec}$ and Ontario paper mill sludge (圈); NF = Noranda Forest paper mill sludge ( $\mathbf{0}) ; \mathrm{S}$ = sand. Vertical bars represent standard error of the mean. significantly more dogwood, cotoneaster, and forsythia growth in $30 \%$ than in $15 \%$ sludge-amended media, differences were small (3\% to 5\%) and, thus, of little practical significance. Height data for dogwood were similar to those of corresponding top dry weight (data not presented). Forsythia and weigela height and cotoneaster width were unaffected by media (data not presented).

In a similar study, in which 'Anthony Waterer' spiraea was grown in bark amended with $0 \%$ to $100 \%$ sludge, a positive linear or curvilinear relationship existed between top dry weight and foliar contents of $\mathrm{N}, \mathrm{P}, \mathrm{K}, \mathrm{Mg}$, $\mathrm{Fe}$, and $\mathrm{Zn}$ (C. Chong, unpublished data). This evidence indicated increasing unavailability of these nutrients as the sludge content of the media increased. With the small proportions of sludge used in the present study ( $15 \%$ or $30 \%$ ), little or no variation was evident in foliar nutrients within cultivars and/or media (data not presented). Bulk densities were consistently higher in NF media than in their QO counterparts and other nonsludge media (data not presented). Differences in total pore space, air pore space, and water pore space at the start of the experiment, or in the relative shrinkage of the media at the end of the experiment, were within acceptable ranges (Ontario Ministry of Agriculture and Food, 1992). These differences generally were neither sufficiently large nor consistent enough to explain growth differences between treatments.

Pridham and Cline (1988) observed that growth of various containerized greenhouse crops in sludge-amended media was related to the amount of $\mathrm{N}$ in the sludge. Related studies with container-grown nursery crops confirmed this observation (Chong et al., 1987, 1988). Growth of 'Anthony Waterer' spiraea was related directly to the initial $\mathrm{N}$ content of various sources of individual or mixed sludges added at 33\% (by volume) to bark (Chong et al., 1988). In the present study, all NF sludge media contained initially high EC levels (4.1 to $\left.7.6 \mathrm{dS} \cdot \mathrm{m}^{-1}\right)$ due primarily to nitrates and, to a lesser extent, $\mathrm{K}, \mathrm{Ca}, \mathrm{Mg}$, and $\mathrm{Cl}$ (in that order) (Table 1). This evidence strongly suggests that growth was related to the initial high $\mathrm{N}$ and nutrient level in the sludge.

Although the EC levels were not monitored at regular intervals in this study, in previous studies that used similar trickle fertigation regimes (Chong et al., 1987, 1991 b), early and rapid leaching of high and potentially toxic salt levels to lower levels considered to be safe for plant culture $\left(\leq 1.0 \mathrm{dS} \cdot \mathrm{m}^{-1}\right)$ (Ontario Ministry of Agriculture and Food, 1992) occurred within 10 to 14 days after planting. As in the present study, initial high salt levels in sludge-amended media did not damage cultivars (Chong et al., 1987). The initial $\mathrm{N}$ contents in the sludges provided ample $\mathrm{N}$ for sludge breakdown and increased crop growth. The difference between NF and QO may be related to the greater availability of inorganic $\mathrm{N}$ in $\mathrm{NF}$ compared with organic $\mathrm{N}$ in QO.

Results of this study confirm that raw paper mill sludge can be used effectively in nursery container culture. Media amended with $15 \%$ or $30 \%$ of two sources of mixed primary and secondary paper mill sludges supported growth of four nursery cultivars similar to, or better than, various nonsludge media.

\section{Literature Cited}

Bellamy, K. 1989. Assessment of soil and water quality at a test agricultural site receiving Fraser Inc. sludge. Ortech Intl., Mississauga, Ont., Rpt. P.88-48-5657/CI.

Bellamy, K.L., N. deLint, N.F. Pridham, and R.A. Cline. 1990. Agricultural utilization of paper mill sludge in the Niagara area. Proc. 13th Intl. Symp. Wastewater Treatment and 2nd Workshop on Drinking Water, Montreal. p. 65-81.

Bockheim, J. G., T.C. Benzel, R-L. Lu, and D.A. Thiel. 1988. Groundwater and soil leachate in organic nitrogen in a Wisconsin red pine planta- 
tion amended with paper industry sludge. J. Environ. Quality 17:729-734.

Chong, C.,R.A. Cline, and D.L. Rinker. 1987. Spent mushroom compost and paper mill sludge as soil amendments for containerized nursery crops. Proc. Intl. Plant Prop. Soc. 37:347-353.

Chong, C., R.A. Cline, and D.L. Rinker. 1988. Use of paper mill sludge in container crop culture. Landscape Trades 10(7): 17-18.

Chong, C., R.A. Cline, and D.L. Rinker. 1991a. Organic wastes as growing media. Proc. Intl. Plant Prop. Soc. 41:315-319.

Chong, C., R.A. Cline, D.L. Rinker, and O.B. Allen. 1991b. Growth and mineral nutrient status of containerized woody species in media amended with spent mushroom compost. J. Amer. Soc. Hort. Sci. 116:242-247.

Cline, R.A. and C. Chong. 1991. Putting paper mill waste to use in agriculture. Highlights Res. Ontario 14(1): 1619.

Henry, C.L. 1991. Nitrogen dynamics of pulp and paper sludge amendment to forest soils. Water Sci. Technol. 24:417-425.

Logan, T.J. and H. Esmaeilzadeh. 1985. Paper mill sludge evaluated for use in cropland. Ohio Rpt. 70(2):22-25.

Ontario Ministry of Agriculture and Food. 1992. Production recommendations for nursery and landscape plants. Publ. 383. Queen's Printer for Ontario, Toronto.

Pridham, N.F. and R.A. Cline. 1988. Sludge disposal: Completing the ecological cycle. Pulp and Paper Canada 89(2): 173-175.

U.S. Environmental Protection Agency. 1991. Proposed regulation of land application of sludge from pulp and paper mills using chlorine and chlorine derivative bleaching processes. Fed. Register 56(91):21,802-21,833.

Zibilske, L.M. 1987. Dynamics of nitrogen and carbon in soil during paper mill sludge decomposition. Soil Sci. 143:26-33. 